\title{
From the individual's fault to the construct of power (Development and changes of crime theories)
}

\author{
Mohamad Seddigh Mohamadi ${ }^{1}$, Hasan Babaee ${ }^{2}$, Mohamad Khaledian ${ }^{3, *}$ \\ ${ }^{1}$ Department of Sociology, Prevention of Crime at the Court of Justice, Kurdistan, Iran \\ ${ }^{2}$ Department of Law, Payame Noor University, PO BOX 19395 - 3697, Tehran, Iran \\ ${ }^{3}$ Department of Psychology, Payame Noor University, PO BOX 19395 - 3697, Tehran, Iran \\ *E-mail address: Mohamad_khaledian22@yahoo.com
}

\begin{abstract}
The present paper aims to explain crime by investigating various theoretical approaches and to show that from the classic era to the recent postmodern theories, a slow but steady cycle of discourse concerning crime has been occurring. In the classic times, the criminal is assumed to be a sane person with sound will who commits crime with an individualistic choice and due to incorrect decisions; In the positivism approach, the theorists' concern is directed at recognizing criminals and clarifying more fundamental biological aspects and psychological performance and they seek to explain the phenomenon of crime by dividing the people of the society into normal and abnormal people; In the modern theories the social factors causing the appearance of crime are at the focal point while critical theories greatly emphasize on the role of the society in the criminal phenomenon and its definition, finally postmodern theories consider crime totally as constructed by mindset, language and power and question its existential reality.
\end{abstract}

Keywords: Crime; Crime theories; Construct; Power

\section{INTRODUCTION}

Various theorists and thinkers have addressed crime and factors affecting its emergence. Some argue it is because of environmental and geographic characteristics while some others maintain psychological and personality factors that affect the commitment of crime. Some emphasize on the role of the society on the appearance of crime and finally some consider crime as constructed by mindset, language and power and try to explain it with a new. An investigation of various theoretical approaches on explaining crime from the classic times up to now reveals interesting insights; for example as time lapses, accusations have turned away from individuals, pointing society, construct of mindset and power to the blame. The present paper, with an overview, provides a mindset of the thinking turnaround on crime, a turnaround that could be regarded a discourse turnaround on explaining crime. 


\section{DEFINITION OF CRIME}

Defining crime is no easy job, some say crime is an act5 that disturbs the social order, but this definition not only solves no problems, but it also transforms one problem into three problems: 1. what is meant by order? 2. What is meant by community? 3. Who would recognize this affair? (Setoode, 2002).

"Some lawyers argue that violating the law of any country through an external act, should it is not prescribed and renders in punishment is called crime" (Tajzaman, 1985). Despite the fact that such concepts as deviancy and crime are highly related, they're not synonymous. Wholly, deviancy is a deviation from social norms. The following definition best specifies a deviant conduct.

"Any act or expression by the members of the society recognized as an offence to group norms is thought to be deviance" (Mohseni, 2007). Hence, in societies wherein there are no established and written laws, the two terms "crime" and "deviancy" are used interchangeably (Salimi and Davari, 2007). Thus, legally speaking, that which engenders a deviant conduct is recognized a crime is the existence of rules. Wherever law exists, so does crime, because the simplest definition of crime is any manner of behavior that breaches law (Giddens, 2004). The Iranian Islamic punishment law defines crime as: "Any act or omission for which punishment is determined is considered crime".

Occasionally, the term crime refers to social deviancies committed by people at a legal age (Ahmadi, 2005). Here, the term delinquency is used for people not reaching the legal age. Cultural criminologists define crime as: "Crime is a human activity or reality which is a product of the social order from a cultural point of view, an order in which we live at any specific point in history".

In other words, "crime involves daily life experiences and behaviors of all members of the society" (Mohseni, 2007).

\section{1. An explanation of crime in the classic times}

The classic model offers a rational version of the human nature upon which man acts with self-motivation. This sort of criminology doesn't deal with an investigation of factors of the human conduct, rather it emphasizes solutions to control and guide this behavior through an effective rational motivation.

Determining social situations was of little value and handling crime was of significance. Basic concepts considered in the classic theory are:

- A presentation of legal and specific definition of crime,

- Emphasis on the fact crime is an act that violates laws and rights of the people and society,

- Main focus of this theory deals with a criminal act and special crimes that occur in the real world.

Here, in this school of thought, the criminal is thought to be a sane person with sound will that commits crime by an individual choice and because of irresponsible decisions (White, 2002).

\section{2. Positivism explanation of crime}

The crime positivism approach is naturalism approach that regards an objective process whose aim is to foresee and control the world. Here, in this sense, most criminology theories 
are modern and naturalism theories (Valad, et al, 2001). The positivism view seeks to explain the deviant and criminal conduct using the scientific rationality (argument). The primary concern of this approach is on criminals and clarifying more basic biological characteristics, psychological performance and their social environment which were different from those of the normal people.

The postulate, upon realizing and measuring these definitions between normal and abnormal people is that predicting delinquency level among the group under debate will be achieved (Brown, 2007). The achievement school id established on the principle of scientific impression regarding crime and criminology. This school assumes that there is distinguished difference between natural and deviant person. Meanwhile, this school seeks to examine special criteria that result in the creation of criminal or deviant conduct (White, 2001).

\section{3. Biological explanation of crime}

The psychological positivism theory was for the first time introduced by Lamberzo's writings. This theorist strove to distinguish different human groups and to classify them based on racial and biological difference. According to this school of thought, the criminal person is born not to become a criminal person. This approach maintained that since the natural female complementary is $\mathrm{xx}$ and the natural chromosome behavior of a person is $\mathrm{xy}$, if a new mix is determined like xxy, the likelihood of being delinquent will increase. Later sciences as phrenology or criminology were taken based on the personal physical structure (White, 2001).

\section{4. Psychological positivism}

Psychological positivism has a distinct historical origin and represents a different orientation on crime and criminal activities. Here, in this school of thought, crime occurs as resulting from biological matters caused by an externality (e.g. war injury) or internal treatable psychological factors. Thus, accordingly, the person becomes a criminal not because he was born a criminal. This view, anyway calls the criminal a patient man and believes in the treatment of the patient. Psychological theory includes several views. Some of these views attach importance to psychoanalysis that addresses conscious and unconscious mind. They attempt to understand how feelings and beliefs influence the personal behaviors. Still some other views have focused on personality characteristics like studies on belligerent states and reactivity and the psychological personality situations as being related with the personal behavior. Some other views, looking at childhood years, and deprivations delve into the problem because they argue deprivations lead to the emergence of personality patterns in later life periods (White, 2001).

\section{5. Psychological-biological explanations of crime}

Some theorists contemporary to Lamberzou present a psychobiological theory on delinquency and call it constitutional psychiatry. The most renowned exponent of Lamberzou's theories is Sheldon. This psychologist categorizes people into three types physically:

a) Endomorph: This type includes people whose major part of their bodies is constituted by fat and in a sense, this type is not only fat and meaty but they also are still soft with small skeleton, short and have slender limbs. They are good natured, obedient and calm and extrovert. 
b) Mesomorph: They enjoy muscular bodies. They're usually stronger, broad chested and have big wrists and hands. They are also active, aggressive and powerful.

c) Ectomorph: They have gauntly, thin and slender bodies. They're skinny and thin and they are delicate, fragile, angry, tender and emotional. These people are introvert and deal with mental activities. Sheldon sought to relate delinquent conduct with the bodily characteristics, assuming the mesomorph bodily state is more appropriate for committing delinquency (Sheikhavandi, 2005).

\section{6. Crime theories in the modern era}

Modern criminology is often considered like the social science disciplines as a subject taking roots in modern ideas (Walklate, 2007). According to the modern idea, man is produced through a scientific body of knowledge that can control nature. In this course, sociology, arising from natural science seeks to find ways to control and handle humans and social life and social issues particularly.

\subsection{Durkheim}

In opposition to the initial criminology view, sociological approaches deal with social and cultural conditions in explaining crime. Durkheim was one of the first people who proceeded to explain crime by adopting a sociological approach. For this, he regarded number and severity of criminal activities in a society as related with power and broadness of a social factor called collective conscience.

"A set of shared beliefs and feelings in the average people of the same society creates a specific system having its own specific life; this system is collective conscience" (Durkheim, 2005). For him, if this force is stronger in a society, number of conducts that trumps a social decree or prohibition become lower (Aron, 2007).

In Durkheim's view, we do not condemn a conduct because it is a crime, rather since we condemn it, it is regarded a crime (Setoode, 2005). No crime is considered crime unless some retribution exists and as a result legal retribution can be exercised unless it is exercised against conducts legally having an exact definition (Shekhavandi, 2000).

\section{8. Merton's pressure theory}

In 1938, Robert K. Merton, the Harvard sociologist published a paper on social structure and anomie and founded his theory on Durkheim's views on anomie and social integrity (Williams, 1982). Merton believes deviation emanates from the structure and culture of the society.

He commences his argument with the standard of the collective consensus about the values and meantime all members of the society contributes to shared values. However, because the members of the society in different positions with regards to social stricture, they don't enjoy equal chances to understand shared values.

Such circumstances would render deviations. In Merton's view, the cultural and social structure of the society creates pressure for the deviant social behavior of the people living in different positions. Anomie, socially speaking, exists in the social system due to construct chasms among desires (shared goals) and actual access (Access to social tools to attain goals).

Merton introduces five ways of activity or adaptation, the first of which is adaptation while the other four, resulting from failure to accept legal goals or instruments are delinquency. 
Table 1. Merton's typology of adaptation manners.

\begin{tabular}{|c|c|c|c|}
\hline Row & Adaptation manner & Goals & Tools \\
\hline $\mathbf{1}$ & Conformity & + & + \\
\hline 2 & $\begin{array}{l}\text { Innovation } \\
\text { (e.g.a robber) }\end{array}$ & + & - \\
\hline 3 & $\begin{array}{l}\text { Event - oriented } \\
\text { (taking the injured to } \\
\text { the hospital and } \\
\text { problems with office } \\
\text { bureaucracy) }\end{array}$ & - & + \\
\hline 4 & $\begin{array}{l}\text { Isolation and } \\
\text { separation } \\
\text { (Person doesn't } \\
\text { accept goals nor tools }\end{array}$ & - & - \\
\hline 5 & $\begin{array}{l}\text { Recalcitrance and } \\
\text { rebellion } \\
\text { (A substitution of } \\
\text { new values and } \\
\text { goals by the person) }\end{array}$ & $-1+$ & $-/+$ \\
\hline
\end{tabular}

(Merton: 1957).

\subsection{Cultural transference theory}

The cultural transfer theory by Gabriel Tarde (1842-1904) introduced the theory of imitation for explaining deviancy.

Tarde was extremely influenced by the fact that repetition would play a significant role in the human behavior. He states criminals like "good" people imitate ways by people, whom they have met, recognized or heard about them, but contrary to people who are subject to law, they imitate other criminals.

Shaw and McKey introduced the term "delinquency area" and state that in poor localities of the cities, delinquent conduct is a normal pattern. In such areas, young men learn about deviant conducts and values and internalize them and as a result they become deviant, because they have friendship and close contacts with people who have themselves been delinquent (Horton and Hunt, 1984).

\section{10. Edwin Sutherland's theory-Differential association}

Sutherland (1882-1950), is a sociologist that has been in collaboration with the Chicago school and founded the theory of differential association. Sutherland claimed some people through processes of socialization are more prone to commit crimes. These people have internalized an orientation toward crimes and have acquired this orientation from groups of whom they've been in close contacts.

There are also sub cultures in which they could learn about ways to commit crimes and conducts contrary to common social conducts are encouraged (Vander Zanden, 1993). 


\section{11. Social control theory}

This theory maintains conformity is a result of social links among the people in a society and of exercise of control by the society on people while it considers disconformity as arising from personal bonds with arbitrary social order. Trause Hirche believes that deviancy is subject to weakness or breaking of the person's obligation to the society.

In his view, there's no need to explain the motivation for delinquency because "we're all creatures that we're naturally capable of committing criminal activities". He states people having strong relation with other groups like families, school and the peers, it is less likely they commit delinquent conducts. He introduced four social rings which are: belief, attachment and obligation, commitment and occupation (Voldo, Bernard, 1996). By belief, it is internalized values, the stronger it is, the less likely deviancy occurs (Horton, Hunt, 1984).

\section{12. The ecological theory of deviancy and the Chicago school}

In modern times and in coincidence with the emergence of modern European cities, a critical and negative approach to the city and internal mechanisms of the cultural, social and economic activities of it with respect to the environmental problems drew the orientation of the European sociologists. At first, the German social scholars like Zemmel and Tonnies in the second half of the $19^{\text {th }}$ century latent began to investigate an aspect of the industrial cities reaming hidden to most of their contemporaries. In fact, they wouldn't regard new cities the sole pivotal centers for development and industrial expansion, rather they believed that the new social and technical expansion pattern, beside the salient physical growth of cities, along with a new materialist life philosophy had caused huge corruption in new cities (Seddighi, 1994).

The Chicago school influenced by these viewpoints and ecology founded its own theories. Ecology refers to the relation between organizations and the environment. Members of the Chicago school applied this sense on the growth of big cities and argued human behavior could be predicted based on urban environment (Glynn, 1988 and Stewart). Ezra Park (1935) argued the main difference between the urban community and rural community being that the city provides the opportunity for its residents so as to complete personal talents. In other words, he states city creates market for the best talents of people (Park, 1979). Shaw and Mckey point out delinquency level corresponds exactly with economic factors (Walmsley D., 1987). On the ground of the Chicago school views, high rate of unsustainable population in a geographic area is a major agent in preventing the formation of a sustainable social environment and as a result salient impacts will be left on the social organization of the residential environment (Haralmbos and Holborn, 1990).

\section{13. Criminal subculture theory}

One of the most famous cultural subcultures is Cohen's theory. The term delinquency subculture appeared for the first time in the book "delinquent boys". To Cohen, major conditions for creation of subculture is existence of action among actors who are in conformity with similar issues. Lower class adolescents adapt with issues that in most situations, particularly at school, they're required to compete based on criteria of middle class. The arbitration of such competition is done by teachers dependent on middle class criteria.

In fact, such a criteria depends on the dominant and affluent class like intelligence and language health, studying well, decorum and neatness. The lower class children, when cannot respect these standards, will be ruled out because primary family education doesn't prepare them for such a competition. This theory make easier an explanation of high delinquency 
among lower society classes. This theory states the adolescents depending on lower class who have little chance to compete with the adolescents' standards of the middle class will apparently resort to a subculture of delinquency so to compensate, in their own manner, the shortfalls.

If emphasis is placed on the issue of continuation and maintenance, then the theory of delinquency subculture will be a useful tool to test some hypotheses to the preferred structures. For instance one can assume that the person would learn the values of the subculture of delinquency in the process of membership and participation in the group proponent to this subculture (White, 2005).

\section{14. Critical theories}

In the critical crime approach, there's nothing to be described so easily by referring to what exists or not. Crime is not a simple conduct of law violation, rater it is a subject constructed by the process of interactive social reaction and power.

\section{15. Labeling theory}

The labeling theory has roots in symbolic reciprocity. The main focus of this theory is on the power of labeling and formation of a deviant identity influenced by this labeling. The well-known theorists of this approach are, Edwin Lemert, Howard Becker and Schur. However, people like Karfingel and Goffman have had stances to explain deviancy through this thinking channel. Becker maintains social groups cause to exist deviancy by some rules which violating them creates deviancy. This occurs by applying these rules for special people and labeling them as strangers.

Deviancy is not the quality of the act by the committer (wrong), rather it is the result of rules application and punishments for a criminal. A deviant is a person for whom this label is successfully exercised. Deviancy is a conduct on which others put a label (Becker, 1963). The social reaction theory emphasizes that by labeling an act as deviant, we create a string of eventualities that drives the person toward larger deviations and finally, throws him into a structure of deviant life (Horton and Hunt, 1984).

On labeling, Lemert distinguished first deviancy from the secondary deviancy .In first deviancy, the person doesn't become deviant, rather it is in the secondary deviancy in which the identity of a deviant person gets a label and particularly he defines deviancy as a way of life for himself. The first deviancy is a state wherein there's no obligation to the deviant character or occupation while in the secondary deviancy, the labeled people organize their conducts based on the social reactions and put a negative label to the society accordingly (Lemert, 1951).

Schur states a successful labeling needs four elements:

Cliché making (stereotype): It is an unchangeable and simple imagination or a pattern caused by definite audiovisual pattern. Labeling, after it occurs, could continue and might need enhancement. This subject occurs when mass media describe a criminal as a "veteran mental patient".

Schur uses the term "retrospective" to describe the process of looking at the past for hiding and revealing the cause of conducts happening in the present times (Schur, 1971). The third element involves bargaining between the labeled person and the labelers. The fourth element is the learning of the role which is a more limited aspect of the secondary deviancy and is related with the social response to the person recognized as a criminal or deviant or 
delinquent. Learning role is a psychological-social process with which the person accepts the "premium position". Learning role is a combination of cliché making, interpretation of the retrospective and bargaining. Goffman and Karfingel enshrined the social reactions in the symbolic reciprocity framework. The major characteristics of this approach is a great emphasis on the power of labeling against marginal, more deprived and less powerful people in a human community and unless there's no such power, crime and criminal will not get formed (Vander Zanden, 1996).

\section{16. Marxist theories}

Contradictory crime theories consider the existing normal consensus in the society and the retribution laws arising thereof as a tool for the social control that are caused by conflicts of the upper class and the oppressed people. For them, the contradictory class interests in a society are more latent than patent (Rossy and Henry, 1980). In his socio-economic analysis, Marx is little concerned with the subject of deviancy and crime while in the book "German ideology" (1845), there is a main section devoted to law, crime and punishment. There, he deals with the explanation of crime and delinquency correlation with the capitalist system and consider them a part of work division in the system (Momtaz, 2008). For Marx, crime is a phenomenon that is capitalist system specific and it will fade away as it changes. Also, Marx applies the term alienation against the Durkheim's anomie to refer to the personality and nature of criminals. This sense is a reflection of social approaches to crime and criminals.

In fact, it is these social reactions that cause the person to feel self-alienation that gradually make him be far away from the society (Ahmadi, 2004). Capitalist system characteristics affect the peoples' attitudes and their appraisals of the criminal activities. There are two main approaches in the contradictory criminology: Instrumental Marxism and structural Marxism. The former approach focuses on the role of law, law enforcers, government and the limitations of the working class. This approach was introduced in the 1960 s and early 1970.

The latter approach was defined as a response to criticisms againsts the instrumental Marxism. Contemporary Marxism theorists like Richard Koeeni, William Chambliss, Barry Cresberg, and Bonger expanded the basic discussions of the instrumentalists. To Bonger, capitalism is a greedy and autocratic system and this excessive capitalism conceit encourages the citizens to seek objectives that meet the capitalists' interests. Koeeni sates crime in the capitalism system has two main facets. 1. working class crimes, 2. Elite crimes. The crimes by the working class include crimes based on compatibility and crimes related to resistance. For instance, in the harmonious offensive crimes, criminals obtain money from their victims. Harmonious offensive crimes include homicide, rape and battery.

Resistant crimes are working peoples' reactions against the exploitation applied by the elite. These crimes are looting and plundering followed by revolutionary and nonrevolutionary objectives. (Winfree, 2003). Kooeni, divides the elite crime activities into three categories: 1. Crimes of domination and oppression to support the interest of the elite, 2 . Criems of control related to police, judicial systems, education and control tools, 3 . Governemnt crimes which are both complicated and important include criminal activities that ignore the citizens; rights and those of the governments.

Kooeni in the book "the theory of social crime reality" emphasizes on the processes of defining crime and he maintains that the nature of crime has the following characteristics in the capitalism system: 1 . Crime is the product of law, 2. Lawmakers are influenced by the most powerful part of the society, 3. Activities in conflict with the interests of the most powerful part of the society are more likely to be introduced as illegal, 4. It is highly having 
no role in the production of law that their conducts to be defied as crime, 5. People whose conducts are defined as crime, see themselves as criminals, 6. Finally, that crime is constructed by a social reality (Neubecke, 2007).

\section{POSTMODERN THEORIES}

\section{1. Postmodern viewpoints in general}

The new sociological theories on deviancies and criminology in the sociology literature and criminology have not drawn much attention in recent several decades in the Iranian academic community and researchers have to a lesser extent addressed the issue of deviancy and crime through these approaches.

From the 1950s onwards, the modern and positivism theories of criminology have seriously been criticized because of their biased and natural sciences based view and in the 1970s, these criticisms were at their highest as critical criminology appeared. New theories, from this decade were concentrative on three elements of mindset, power and discourse. labeling, contradiction, postmodern and feminist and cultural criminology theories were among the most important new critical approaches in explaining crime with these elements in their hearts.

Of course, the postmodern criminology, while being critical, it is categorized beyond the other critical criminology, because other approaches don't criticize the modernism approaches and modern criminology while postmodern criminology rule out the whole of modernism and its control look over it. Postmodernism presents a vague, pluralist and temporal approach of the social world and questions the immense and absolute realities that were sought by modernism. Hence, the whole modernism criminology project was a deceiving one. The inclination of this approach was on grounds and senses that change from one place to the latter not on singularities (Carrabine, 2004).

Thus all the theories striving to find out the root causes of crime in the modern era with a positivism approach were not acceptable, rather criminology theories are always local, partial, random and are influenced by power and cannot reveal the absolute reality of crime (Carrabine, 2004). Postmodernists examine the relation between the human agent and language in creating sense, identity, justice, power and wisdom. In their view, the social reality is adrift, and is constantly being created and this prevails some through language and discourse, manipulating their opinions and values through language (Brown, 2007).

\section{2. Michel Foucault}

One of the theorists that challenges the modern criminology with a postmodern view is Michel Foucault. He, by analyzing discourse, sees power at the back of any explanatory theory of crime. Foucault in most cases, opposes criminology and was anti-criminology as a philosopher of the history of ideas. In his view, the duty of a criminologist is not really to solve a crime, rather it is on development, and organization of power and supervision.

He considers criminology as a discourse that expands supervision and power relations. Foucault refers to a generalized discourse that for him, correcting the prisoners, detaining the insane, and supervising the industrial workers like education of children are all part of an emerging prison like society. In this society not only crime but also irregularities or breaching norms are controlled (Muncie, 2004). Foucault compares the change of punishment facets in the classic societies (bodily persecution) to the subculture of capitalism modern societies (focusing on supervision, classification and norm making). 


\section{3. Henry and Milanovic}

The basis of the crime nature socially constructed and formed as a discourse is an unequal power relation. Henry and Milanovic focus much on the element of power. For them, crime is "the ability to reject others' abilities to create difference" (Carrabine, 2004). Crime leads to domination whether by some special people(e.g. robbers) or by collective groups (organized criminals) or by states (e.g. mass destruction). Hence, the main source of problematic relations arise from power structures. Unequal power relations create situations that define crime as a damage.

\section{4. Cultural criminology}

Cultural criminology is an interventionist, methodological and theoretical approach in studying the crime being media that puts its criminality and control in the cultural area and crime considers institutions and relevant organizations devoted to controlling crime as cultural products. Cultural criminology, emphasizing on such cases as situational sense, adolescents' culture, identity, milieu, media style and culture, attempts to create a postmodern an recent modern theory (Muncie, 2004).

The most important characteristics of this approach are :explanations related to convergence of processes and crime and culture being dynamic in daily life, combination of subjects of cultural issues, postmodernism, critical criminology, reciprocity, anarchism, and discourse /textual/ media discourse, using the popular methodology to explain subjects of meaning and representation, examining the deviant subcultures, explaining the role of emotional feelings, leisure time, and indulging in crime processes.

\section{CONCLUSIONS}

As time lapses, accusations have turned away from individuals, pointing society, construct of mindset and power to the blame. The psychological positivism theory was for the first time introduced by Lamberzo's writings. This theorist strove to distinguish different human groups and to classify them based on racial and biological difference. According to this school of thought, the criminal person is born not to become a criminal person. In 1938, Robert, K, Merton, the Harvard sociologist published a paper on social structure and anomie and founded his theory on Durkheim's views on anomie and social integrity (Williams, 1982). Merton believes deviation emanates from the structure and culture of the society. He commences his argument with the standard of the collective consensus about the values and meantime all members of the society contributes to shared values.

Thus all the theories striving to find out the root causes of crime in the modern era with a positivism approach were not acceptable, rather criminology theories are always local, partial, random and are influenced by power and cannot reveal the absolute reality of crime (Carrabine, 2004). Postmodernists examine the relation between the human agent and language in creating sense, identity, justice, power and wisdom.

In their view, the social reality is adrift, and is constantly being created and this prevails some through language and discourse, manipulating their opinions and values through language (Brown, 2007). Foucault in most cases, opposes criminology and was anticriminology as a philosopher of the history of ideas. In his view, the duty of a criminologist is not really to solve a crime, rather it is on development, and organization of power and supervision. 


\section{References}

[1] Aron R. (2003). Stages of fundamental thinking course in sociology, (Trans.by Bagher Parham), Tehran: Scientific and cultural publications.

[2] Giddens A. (1990). Sociology theories, (Trans, by, ManoocherSaboori), Tehran: Neipublications.

[3] Ahmadi H. (2005). Sociology of deviations, Tehran: SAMT publications.

[4] Durkheim E. (2000). Social work division, (Trans.by Bagher Parham), Tehran: Markaz publications.

[5] Park E. (1979). Concept of city, theories on examining city, human conduct in the urban environment, (Trans.by GeetiE'temad), Tehran: Iran Nashr publications.

[6] Tajzaman D. (1985). Who's criminal? What is criminology?, Tehran: Keihaninstitute.

[7] Davar Sh. (2000). Sociology of deviancies and social issue, Mashhad: Narandiz publications.

[8] Durkheim E. (2005). On social work division, (Trans.by Bagher Parham), Tehran: Markaz publications.

[9] Seddigh R. (1993). Urban sociology, textbook papers, Tehran: Jahad Daneshgahi publications, Tehran University, Sociology branch.

[10] Giddens A. (2004). Sociology, Trans. by Manoochehr Saboori, Tehran: Nei publications.

[11] Moheni M. (2007). Sociology of social deviations, Tehran: Tahoori publications.

[12] Momtaz F. (2008). Social theories, theories and viewpoints, Tehran: Enteshr Company.

[13] Setoode H. (2001). Social 1 pathology, Tehran: Avayenoor publications.

[14] Vold G., Benard, T., Snips G. (2000). Theoretical criminology, (Trans.by Roohola Seddigh Bathaee Asl), Tehran: Dadgostar publications.

[15] White R., Fionta H. (2004). An introduction to crime and criminology, Tehran: SAMT publications.

[16] Becker H. (1963). Outsiders: studies in the sociology of Deviance, New York: free/ press.

[17] Brown S. (2005). Understanding youth and crime, open university press, McGrowhill education.

[18] Carrabine E., Paul I., Maggy L., Ken P., Nigel S. (2004). Criminology: a sociological introduction, published by Rutledge.

[19] Haralambos M., Holborn M. (1990). Sociology: Themes and Perspectives. London: Road wick.

[20] Horton P. B., Hunt C. C. (1984). Sociology. International Student Edition. 6th ed. Singapore: McGraw-Hill Inc.

[21] Lemert E. (1951). Social pathology, New York, MC Graw-hill Muncie, Jhon 2004, Youth \& Crime, sage publication.

[22] Merton R. (1957). Social Theory and Social Structure. Glencoe, IL: The Free Press. 
[23] Neubeck K., Marry N., Davita G. (2007). Social problems: a Critical approach, the McGraw Hill companies.

[24] Rossi P. H., Henry J. P. (1980). “Seriousness: A Measure for All Purposes?” in M.W. Klein and K.S. Tielmann Ed Handbook of Criminal Justice Evaluation, pp. 489-505. Beverly Hills, CA: Sage.

[25] Schur E. (1971). Labeling Deviant Behavior: its sociological implications, New York, Harper and row.

[26] Vander Z., James W. (1993). Sociology: the core, McGraw Hill.

[27] Vold G. B., Bernard H., Thomas J. (1986). Theoretical criminology, Oxford University Press New York.

[28] Walklate S. (2007). Understanding Criminology: Current Theoretical Debates, Open University prees, McGraw Hill.

[29] Walmsley D. (1987). Urban Living: The Individual in the City. U.S.: Longman, Gohn Wiley.

[30] Williams J., Hall E. (1982). Criminology and Criminal Justice, Lexis Law Publishing.

[31] Winfree T., Howard A. (2003). Understanding Crime, Wadsworth/Thomson learning. 